\title{
La relación género y cooperativa en el ordenamiento jurídico cubano. Una aproximación a su realidad y a sus perspectivas ante el proceso de perfeccionamiento del modelo económico en el país
}

\author{
Orisel Hernández Aguilar ${ }^{1}$
}

Sumario: I. Una introducción necesaria. II. Género, un concepto complejo y con múltiples implicaciones. III. Potencialidades de las cooperativas para desarrollar un adecuado enfoque de género: 3.1. Las cooperativas como institución jurídica. 3.2. Cooperativa y género. Principios cooperativos y posibilidades para desarrollar un enfoque de género. IV. La perspectiva de género en Cuba. Condiciones materiales y tratamiento legal. V. Situación actual de la relación género y cooperativa en Cuba. VI. Género y cooperativa: potencialidades ante la regulación de nuevas formas de cooperativas en Cuba. VIII. A modo de conclusión. Bibliografía.

Resumen: El objetivo de este trabajo es aportar algunas valoraciones en torno a la actual situación de la relación género y cooperativa dentro de los marcos normativos en los que se desarrolla la cooperativa en Cuba, así como sus potencialidades ante una regulación legal que instrumente una ampliación de dichas prácticas como parte de la reestructuración del modelo económico previsto en los Lineamientos de la Política Económica y Social del Partido y la Revolución aprobados por el VI Congreso del Partido Comunista de Cuba y que regirán durante los próximos años las transformaciones emprendidas por el país.

Palabras clave: cooperativa, género, lineamientos y marco jurídico.

Abstract: The aim of this study is to provide some comments about the current situation of the relationship the gender and the cooperative within the frameworks within which the cooperative develops in Cuba, as well as their

1 Máster en Derecho Constitucional y Administrativo, Profesora de Teoría General del Derecho y Derecho Romano, Departamento de Derecho, Facultad de Ciencias Sociales y Humanísticas, Universidad de Pinar del Río, Cuba. E-mail: oriselha@fcsh.upr.edu.cu 
potential in front to a legal regulation that implements an extension of such practices as part of the restructuring of the economic model provided in the Guidelines of the economic and Social Policy of the Party and the Revolution adopted by the sixth Congress of the Communist Party of Cuba to guide during the next years the changes undertaken by the country.

Key words: cooperative, gender, guidelines and legal framework. 


\section{Una introducción necesaria}

El planteamiento de género en el sector productivo y laboral ha tenido grandes progresos pero aun no alcanza los niveles que permitan afirmar la perfecta consecución de una igualdad que parta del respecto a las diferencias naturales que existen entre mujeres y hombres y sus consecuentes roles.

El ámbito de lo productivo ha estado, y aún está, regido por reglas dictadas en función de la eficiencia y la ganancia, lo que supone un tratamiento incompleto de los principios de respeto y promoción de la mujer, ya que más bien promueven su asimilación a modos de actuar e ideales de éxito masculinos.

La regulación legal de las cuestiones de género no ha podido transformar las disposiciones respecto a la igualdad en un cambio real de las conductas dentro del ámbito laboral en un mundo dominado por el «eficientismo productivo», a pesar de que casi todas las normativas actuales han reconocido, en términos generales, la aspiración de alcanzar un tratamiento equitativo de género.

A pesar de estas limitaciones al Derecho le corresponde desempeñar un rol coadyuvante en la transformación de esta situación, rebasando las simples concepciones normativistas y poniéndose al servicio de la promoción, desde el plano legal, de alternativas que posibiliten un cambio en la conciencia social de la que forma parte ${ }^{2}$ en pos de desarrollar «su posible función transformadora.» ${ }^{3}$

Ante esta situación se presenta una forma de organización, producción y apropiación que promueve, o puede promover, desde su diseño, importantes valores agregados a la eficiencia productiva y la socialización de la producción, entre lo que puede estar un mejor tratamiento de género: las cooperativas.

2 «...el Derecho forma parte de la conciencia social y dentro de ella ocupa un lugar singular: las ideas sobre el Derecho, la expresión del fenómeno jurídico en la conciencia social se identifica como la conciencia jurídica, que no es más que la apreciación de la sociedad sobre los principales valores jurídicos, es decir, sobre la justicia, lo justo, lo legal, lo ilegal, etc.» Fernández Bulté, J: Teoría del Estado y el Derecho. Segunda Parte Teoría del Derecho, Editorial Félix Varela, La Habana, 2004, p. 22.

3 MASINO, M.A. "Los aportes de Antonio Gramsci para una epistemología materialista del Derecho» publicado en Introducción a la epistemología del Derecho. Dirección de Publicaciones, Universidad Nacional del Rosario, 1988, p. 124. 


\section{Género, un concepto complejo y con múltiples implicaciones}

Para una comprensión más cabal del fenómeno debe aclararse su connotación y su diferencia respecto a la categoría sexo. Se entiende por sexo al conjunto de características físicas, biológicas y corporales que definen, dentro del género humano, a hombres y mujeres. En tanto que género designa al conjunto de características psicológicas, sociales y culturales socialmente asignadas a las personas. Estas características son históricas, se van formando con el tiempo y por tanto son modificables lo que implica que «la perspectiva de género no suprime las diferencia entre hombres y mujeres. ${ }^{4}$

ENGELS en su libro «El origen de la familia, la propiedad privada y el Estado» pone al descubierto los orígenes mismos de las cuestiones de géneros y su complejidad al revelar que el origen de la exclusión social y la subordinación femenina guarda una relación directa con el surgimiento de las clases sociales. Esto es un resultado de la aplicación de «uno de los principales postulados marxistas, considerado como «núcleo duro» de su teoría, el condicionamiento social de los fenómenos» ${ }^{5}$, que pone de relieve el peso del «influjo del orden material sobre el pensamiento y las conductas humanas, se encuentra en las raíces del término "género».» ${ }^{6}$

No muy lejos de esta lógica de pensamiento se ubica el enfoque integrado de género o mainstreaming, que ha sido la más reciente y completa opción que se ha adoptado para el tratamiento de género, una vez que se ha arribado al convencimiento de que solo es posible superar estos vicios históricos con un trabajo sistémico.

El Mainstreaming ${ }^{7}$ es un término sobre el que no existe consenso pero que ECOSOC define como «el proceso de valorar las implicaciones que tiene para los hombres y para las mujeres cualquier acción que se planifique, ya se trate de legislación, políticas o programas, en todas las áreas y en todos los niveles. Es una estrategia para conseguir que las preocupaciones y experiencias de las mujeres, al igual que las de los hombres, sean parte integrante en la elaboración, puesta en marcha, control y evalua-

4 Tshibilond Ngoyl, A.: «La filosofía y los problemas de género en África». Temas n. os 37-38/abril-septiembre de 2004, p. 19.

5 Pérez Rolo, Marta y Díaz, Elena. «Estudio sobre los valores de dirección y de género en las cooperativas cubanas», Cuaderno pedagógico, volumen 2. IRECUS FLACSO/ CUBA, Université de Sherbrooke Universidad de La Habana, uniRcoop, 2006, p. 59.

6 Ibidem.

7 Mainstreaming de la actuación y de la paridad, las primeras definiciones de esta estrategia se hicieron en las Conferencias Mundiales de las Naciones Unidas: la tercera en 1985, en Nairobi, y la cuarta, en 1990, en Beijing. 
ción de las políticas y de los programas en todas las esferas políticas, económicas y sociales, de manera que las mujeres y los hombres puedan beneficiarse de ellos igualmente y no se perpetúe la desigualdad. El objetivo final de la integración es conseguir la igualdad de los géneros. $»^{8}$

Uno de los espacios donde más urge a las mujeres un enfoque de este tipo es en el laboral, en el que se ponen de relieve como aspectos de otros ámbitos de la vida interfieren y condicionan el desarrollo profesional, poniendo de manifiesto a su vez que «hay decisiones políticas aparentemente no sexistas, pero que pueden tener un diferente impacto en las mujeres y en los hombres, aun cuando esta consecuencia ni estuviera prevista ni se deseara. Esto hace necesario, por tanto, que cada actuación pública deba ser analizada en términos del impacto diferencial que tendrá en el colectivo femenino y en el masculino. $»^{9}$

Con la inclusión de las féminas en el mundo laboral se alcanzó una gran conquista, pero esta aún no ha logrado trascender lo suficiente porque el mundo laboral no adaptó plenamente sus exigencias para incluirlas, sino que le exigió que demostrara la capacidad de un hombre para desempeñarse, de hecho «la mujer se ha incorporado a la sociedad activamente, pero a un gran costo personal. Ha tenido que asumir múltiples tareas y nuevas responsabilidades y necesitado de mayor esfuerzo y entrega para poder cumplir como madre, esposa y «mujer trabajadora asalariada» »10, pagando el precio de esa independencia con una doble vida: en el ámbito privado y en el profesional.

Es por ello que no puede pretenderse que un trato igualitario sea suficiente. Se impone que la legislación reconozca la necesidad de determinadas desigualdades justas, dentro de la igualdad general, pues «...hay desigualdad y desigualdades, y que lo que determina esta división es el tipo de diferencias que los hace justos e injustos... teniendo presente las desigualdades reales, no justificadas por diferencias relevantes, hay que dar la prioridad a la igualdad concreta que se contrapone a esas desigualdades. Si, por el contrario, se trata de igualdades que no se justifican, la prioridad corresponde a las desigualdades que esa igualdad desatiende u oculta. Pero, lo que determina, en definitiva, que es lo prioritario, en una situación histórica determinante, si la igual-

8 Glosario de términos relacionados con la transversalidad de género. Proyecto Equal «En clave de culturas», Secretaría Técnica del Proyecto Equal «En clave de culturas», 2007.

9 Astelarra, J. «Estado y políticas de género», publicado en Temas n. ${ }^{\text {s }}$ 37-38/abrilseptiembre de 2004, p. 93.

10 Rodríguez ReYES, I. «Relaciones de género en la familia cubana: ¿espacio de igualdad o desigualdades?», Temas n. ${ }^{\circ} 48$, octubre-diciembre de 2006, p. 116. 
dad o la desigualdad, y que rasgos comunes o diferentes justifican un trato igual o desigual, se hace de acuerdo con el valor que le atribuiremos-como justo o injusto-dentro de un proceso incierto y aleatorio de emancipación humana.» ${ }^{11}$

Así, dentro del ámbito de la igualdad general, debe concebirse una igualdad como principio que respete aspectos concretos de desigualdad justa y justificada que eviten la discriminación, tanto por exceso como por defecto, y que en el plano donde se manifiestan las diferencias justificadas de posibilidades entre féminas y hombres respeten estas y se le creen las condiciones para armonizar su pleno desarrollo, o sea, se dé un adecuado tratamiento a los límites ${ }^{12}$ propios de su condición y se ponga fin a las limitaciones ${ }^{13}$ de que ellos se han derivado.

Resumiendo lo hasta aquí expuesto se puede afirmar que:

- La complejidad de la categoría género, sus condicionantes y consecuencias explican que la política a seguir en el tratamiento de estas cuestiones no haya sido simple de determinar y solo sea viable una alternativa de tratamiento que comprenda la posibilidad de enfrentar cada una de sus aristas, para lo cual no existen medidas unidireccionales, más allá de que determinas estrategias enmarcadas en ellas puedan serlo.

- En el ámbito laboral es donde, con mayor claridad, se evidencia la colisión entre la realización personal y profesional de la mujer, porque los moldes de género que imperan como paradigmas en ambas esferas son contradictorios, lo que hace suponer un esfuerzo doble para conciliarlos. Por ello es necesaria una forma de relaciones laborales que asimilen las necesidades de desarrollo personal de las féminas y las de un espacio para su desarrollo profesional.

Es en este panorama donde podría entrar la cooperativa a representar una alternativa al enfoque de género tradicional dentro de la es-

11 SÁNCHez VÁZqueZ, A. «Reflexiones- ¿intempestivas?: sobre la igualdad y la desigualdad». En Entre la realidad y la utopía, Editorial de Ciencias Sociales, La Habana. p. 93.

12 Los límites son una consecuencia natural del objeto o fenómeno que se estudia. En el caso del desempeño de las féminas estas tienen roles, unos que les han sido asignados socialmente y otros derivados de las funciones históricas, que son patrimonio de las mujeres y que no deben constituir una causa de discriminación (V. gr. la mujer es la única que puede ser madre).

13 Las limitaciones son consecuencias externas al hecho o situación que se estudia que le impiden su máxima realización. Dentro del desempeño laboral pleno de la mujer la más evidente es la concepción de que es ella la que debe incorporarse más, sin comprender que también la sociedad y el Derecho deben adaptarse a la realidad y naturaleza femeninas. 
fera de las relaciones laborales, pero con una proyección y alcances que claramente rebasan este ámbito.

\section{Potencialidades de las cooperativas para desarrollar un adecuado enfoque de género}

\subsection{Las cooperativas como institución jurídica}

Al respecto no existe un criterio uniforme. Puede ser enfocado de diversas formas según se entienda que su esencia radica en el hecho de que esta es una empresa (ya que consiste en una actividad económica); una asociación (pues parte importante de su definición es el hecho de que supone una integración de un grupo de personas que persigue un fin común de carácter productivo) o una forma de propiedad (porque implica una forma particular de relación con los medios de producción).

Aunque no se pretende sentar doctrina al respecto en este artículo debe dejarse en claro que ninguno de los aspectos tratados es desdeñable, por lo cual la cooperativa debe ser entendida como todas esas cosas, sin excluir ninguna. ${ }^{14}$

Lo que sí es cierto es que la cooperativa, como asociación voluntaria de personas en torno a un fin productivo en la que se socializa la propiedad y la producción para el bien de la colectividad, tiene más de una potencialidad a desarrollar en la construcción de una sociedad más justa y el plano del tratamiento de género no es la excepción.

\subsection{Cooperativa y género. Principios cooperativos y posibilidades para desarrollar un enfoque de género.}

Las cooperativas en su configuración se atienen a una serie de principios esenciales para garantizar que esta mantenga su esencia. Entre dichos principios figuran el de asociación abierta y voluntaria ${ }^{15}$, el

14 Al respecto, consúltese Rodríguez Musa, O. La cooperativa como figura jurídica. Perspectivas constitucionales en Cuba para su aprovechamiento en otros sectores de la economía nacional diferentes al agropecuario. Dikinson S.L., Madrid, 2011, pp. 41-52.

15 «Las cooperativas son organizaciones voluntarias, abiertas para todas aquellas personas dispuestas a utilizar sus servicios y a aceptar las responsabilidades que conlleva la asociación, sin discriminación de género, raza, clase social, posición política o religiosa». $\mathrm{ACl}$. «Declaración Sobre la Identidad Cooperativa», Manchester, septiembre de 1995, reproducida y comentada por El Hogar Obrero: Cooperativa de Consumo, Edificación y Crédito, Ltda., en http://www.elhogarobrero1905.org.ar, consultada en diciembre de 2009. 
de democracia ${ }^{16}$ y el de educación, capacitación e información ${ }^{17}$ que permiten completar un círculo de tratamiento integral de las cuestiones de género, si estas se enfocan adecamente, desde la inclusión de las socias, su participación y superación dentro del marco cooperativo, pues es impensable una entidad de asociados democráticamente organizados en la que no se considere medular la integración de todos sus miembros, con todas sus características, incluidas las de género, como elemento esencial para su credibilidad, legitimidad, eficiencia y eficacia.

Dentro de la lógica de funcionamiento que describen estos principios para la entidad cooperativa se pueden concebir formas alternativas a las imperantes de dar tratamiento a la cuestión de género, para lo cual es necesario que se haga de estos una adecuada regulación legal que permita su adecuada comprensión y realización.

Algunos criterios que se pueden tener en cuenta para el tratamiento de género dentro de las cooperativas se relacionan a continuación, sin que por ellos puedan considerarse como un catálogo cerrado. Las cooperativas pueden implementaras, desde su naturaleza flexible, democrática y social, creando un beneficio, no solo empresarial en su desenvolvimiento, al hacer más activos y capaces a sus miembros, sino reportando, además, una importante contribución a la sociedad al propiciar con su incidencia en el enfoque de género un tratamiento integral.

- En la cooperativa, como los estatutos no se imponen desde fuera sino que son de creación colectiva, se pueden adecuar a las necesidades y exigencias, particulares y cambiantes, del colectivo que la integran, incluidas las mujeres.

- La realización del principio de igualdad permite a las mujeres asumir responsabilidades y ejercitarse en la participación por medio de la emisión de criterios y proposición de ideas, valorizando sus aportes, con lo que se les prepara para devenir en ciudadanas activas, se les dignifica y da reconocimiento.

16 «Las cooperativas son organizaciones democráticas controladas por sus asociados, quienes participan activamente en la definición de las políticas y en la toma de decisiones. Los hombres y mujeres elegidos para representar a su cooperativa responden ante los demás asociados. En las cooperativas de base las personas tienen igual derecho de voto (un asociado, un voto), mientras las organizaciones cooperativas de otros niveles también están organizadas con base en procedimientos democráticos». $\mathrm{ACl}$, ob. cit.

17 «Las cooperativas brindan educación y capacitación a sus asociados, a sus dirigentes electos, gerentes y empleados, de tal forma que contribuyan eficazmente al desarrollo de sus cooperativas. Las cooperativas informan al público en general, particularmente a jóvenes y creadores de opinión, acerca de la naturaleza y beneficios del Cooperativismo.» $\mathrm{ACl}$, ob. cit. ISSN: 1134 - 993X, Núm. 46/2012, Bilbao, págs. 297-320 
- Tiene la posibilidad de desarrollar actividades de promoción, educación e inclusión pues la naturaleza del objeto social de estas, dada su amplitud, les permite realizar diferentes acciones en pos de la superación de las mujeres miembros, así como llevar a cabo campañas de divulgación para la comunidad.

- Puede instituir horarios flexibles para la realización del trabajo, que sin afectar la eficiencia de la productividad, permitan el desarrollo de todas las actividades necesarias para el pleno desenvolvimiento de sus miembros mujeres ${ }^{18}$.

- Debe prever para la celebración de sus reuniones de un grupo de condiciones que permitan hacer efectiva y eficiente la participación de las mujeres, entre estas deben considerarse la cercanía y accesibilidad del lugar y horarios que respeten sus otras responsabilidades.

De lo expuesto se colige que:

- Las cooperativas tienen una especial aptitud para enfocar en su desarrollo un tratamiento de las cuestiones de género desde una perspectiva más favorable que otras formas empresariales, pues desde la configuración misma de sus principios están favorablemente condicionadas, solo es cuestión de aprovecharla de forma coherente y consecuente, partiendo para ello de una regulación legal afín con sus principios.

Estas potencialidades no son indiferentes a la realidad cubana, que ha armonizado la inclusión de la figura cooperativa con una importante labor en el tratamiento de las cuestiones de género en los últimos 50 años.

18 «La conciliación —entendida como algo igualitario tanto para mujeres como para hombres- es otro de los aspectos claves en los que las cooperativas dan el ejemplo...».

«(...) es importante la flexibilidad a la hora de poner reuniones», concluye GóMEZ. «Nosotros teníamos muy claro cuando formamos la empresa que debíamos dejar tiempo para todo. Ahora, por ejemplo, gestiono la agenda de mis reuniones para que coincida cuando voy a Sevilla. No es algo que me impongan a cualquier hora y cualquier día, como sucedería con un jefe. Son valores añadidos que no nos los da una empresa capitalista».

«Resulta de interés reseñar que mientras en 2004 las mujeres directivas, en su mayor número, no tenían hijos, actualmente estas mujeres tienen dos hijos», concluía CoCETA en la presentación del último estudio sobre la mujer, en 2009. "Cabría, tal vez, pensar que ello es debido a un progreso en la conciliación de la vida familiar y laboral, que posibilita que las mujeres puedan acceder a categorías laborales más cualificadas, asumiendo la maternidad de una forma responsable».

VILNITZKY, M. et al. Mujer y cooperativismo, consultado en http://www.empresaytrabajo.coop/024/dos02401.asp en fecha 27 de abril de 2012. 


\section{La perspectiva de género en Cuba. Condiciones materiales y tratamiento legal}

En Cuba a partir del triunfo revolucionario de enero de 1959 se trazaron importantes políticas para lograr la participación e integración social femenina. En este sentido la labor de la Federación de Mujeres Cubanas (FMC) ha sido vital.

Muchas cifras pueden dar testimonio de los resultados alcanzados, en el plano de la salud (mortalidad materna 29,9 RMM ${ }^{19}$ ), la esperanza de vida al nacer (77,97 años con una sobrevida femenina de 4,02 años $^{20}$ ), la formación académica y la ocupación profesional (las mujeres son el $43,3 \%$ de la fuerza laboral, el 66,1\% de la fuerza técnica, el 27,6\% de los parlamentarios ${ }^{21}$ ).

No obstante esto no implica la superación de la clásica división de funciones entre roles pues subsiste «el mantenimiento sobre ella de la carga doméstica y familiar a pesar de su protagonismo social». ${ }^{22}$ Situación que se agudizó con la crisis económica a que se enfrentó el país desde principios de los 90 y que aún continua, aunque ha experimentado una distensión en los últimos años con el impacto directo en la vida doméstica de políticas estatales dirigidas a mejorar las condiciones de las labores hogareñas.

En el plano legal, desde el cuerpo normativo de más alto rango se apuesta por la igualdad. La Constitución parte de un reconocimiento general de la igualdad que incluye las perspectivas de género ${ }^{23}$ para

19 Este es índice del periodo 2000-2004. (RMM = Razón de Muerte Materna por 100.000 nacidos vivos). Fuente: 1950-1959: Anuario Demográfico; 1960-1979: Formulario de la OPS; 1980-2004: Dirección Nacional de Estadísticas, MINSAP. Citada por CABEZAS CRUZ, Evelio. "Evolución de la mortalidad materna en Cuba». Revista Cubana Salud Pública, Ciudad de La Habana, v. 32, n. 1, marzo de 2006. Disponible en http://scielo.sld. cu/scielo.php? script=sci_arttext\&pid=S0864-34662006000100005\&lng=es\&nrm=iso, consultada el 19 de mayo de 2012.

20 MINSAP. Anuario Estadistico de Salud 2010. Consultado en http://files.sld.cu/dne/ files/2011/04/anuario-2010-e-sin-graficos1.pdf, en fecha 26 de mayo de 2012.

21 CARAM LeÓn, T. Empoderamiento femenino en Cuba. Criterios para su análisis en las Cooperativas. FLACSO-Cuba, p. 1, publicado en http://www.flacso.uh.cu/sitio_ revista/num2/articulos/art_TCaram.pdf, consultado en fecha 25 de mayo de 2012.

22 Ibídem.

23 Artículo 41. Todos los ciudadanos gozan de iguales derechos y están sujetos a iguales deberes.

Artículo 42. La discriminación por motivo de raza, color de la piel, sexo, origen nacional, creencias religiosas y cualquier otra lesiva a la dignidad humana está proscrita y es sancionada por la ley.

Las instituciones del Estado educan a todos, desde la más temprana edad, en el principio de la igualdad de los seres humanos. 
luego particularizar, detallando puntualmente algunas garantías explicitas para las mujeres. ${ }^{24}$

En materia de legislación laboral se aprecia claramente como el tratamiento de género ha tratado de tomar en cuenta las desigualdades justificadas entre géneros.

El artículo 3.b) del Código de Trabajo 25 establece el acceso libre de discriminación a la oportunidad del trabajar y el principio se reafirma desde otro enfoque en el inciso (h) ${ }^{26}$ estableciendo igual salario a igual capacidad productiva y desempeño, en perfecta consonancia con el planteamiento constitucional respecto al principio de igualdad.

En la Sección I del Capítulo VIII artículo $210^{27}$ se demuestra la presencia del principio discriminación positiva, al reservar a las féminas algunas actividades preferenciales, por estar asociadas a aptitudes naturales de esta.

En cuanto a desigualdades justificadas el Código realiza una consecuente regulación de las condiciones de trabajo, deber de la entidad laboral, necesarios para la mujer, que no traen otra causa que las de naturaleza bio-fisiológicas. En la Sección III Protección Especial a la Mujer

Constitución de la República de Cuba, consultada en http://www.parlamentocubano. cu/index.php?option=com_content\&view=article\&id=1418\&ltemid=83 en fecha 25 de mayo de 2012.

24 Artículo 44. El Estado organiza instituciones tales como círculos infantiles, semiinternados, internados escolares, casas de atención a ancianos y servicios que facilitan a la familia trabajadora el desempeño de sus responsabilidades.

Al velar por su salud y por una sana descendencia, el Estado concede a la mujer trabajadora licencia retribuida por maternidad, antes y después del parto y opciones laborales temporales compatibles con su función materna.

Ibídem.

25 Artículo 3. Los principios fundamentares que rigen el derecho laboral cubano son los siguientes: (...) b) todo ciudadano en condiciones de trabajar, sin distinción de raza, color, sexo, religión, opinión política u origen nacional o social, tiene oportunidad de obtener un empleo con el cual pueda contribuir a los fines de la sociedad y a la satisfacción de sus necesidades;

Ley n. ${ }^{\circ} 49$ Código de Trabajo, publicada en http://www.parlamentocubano. cu/index.php?option=com_content\&view=article\&id=264:ley-no-49-codigo-detrabajo\&catid=46:leyes\&ltemid=79 y consultada en fecha 30 de mayo de 2012 .

26 Artículo 3: (...) ch) las personas tienen acceso, según sus méritos y capacidades, a los cargos y empleos y perciben igual salario por igual trabajo.

Ibídem.

27 Artículo 210. La administración de la entidad laboral, en los casos en que se requiera ocupar, mediante nuevos ingresos, plazas vacantes correspondientes a las declaradas preferentes para mujeres, y siempre que haya concurrido fuerza de trabajo femenina con los requisitos exigidos para el desempeño de esas plazas, debe ocuparlas con mujeres.

Ídem. 
adopta otra serie de previsiones acordes a las características naturales del sexo femenino, estas son referidas en particular al período de gravidez.

La regulación de la Sección IV Protección a la maternidad ha progresado significativamente con el Decreto Ley 234 de 2003 que permite compartir a los padres las responsabilidades de la crianza de los hijos desde los primeros momentos bajo un régimen de protección similar al de las madres, convencionalmente practicado 28 .

En cuanto a la defensa de los derechos laborales y el respeto a la igualdad se podrá exigir por el procedimiento de reclamación de derechos contra la entidad.

Estas legislaciones dan muestra de una decidida intención de respetar y promover una verdadera realización femenina que incluye el respeto a ese conjunto tradicional de tareas femeninas propias de su naturaleza y que pasa necesariamente también por la promoción y concepción de espacio y tiempo para que los hombres se desempeñen dentro del plano del hogar.

Lo antes descrito nos permite sostener que:

Cuba presenta un panorama en el que existen unas excelentes bases materiales y legales, a pesar de los vicios culturales subsistentes, para aprovechar todas las alternativas posibles a fin de hacer un tratamiento más completo de las cuestiones de género.

Una oportunidad que se puede presentar en breve podría venir asociada a la apertura del campo de la cooperativa hacia otros sectores distintos al agropecuario. En todo caso una referencia inicial para asimilar esta novedad habría que encontrarla en la realidad actual de la cooperativa en Cuba, que debe ser tomada en consideración como punto de partida y de superación.

\section{Situación actual de la relación género y cooperativa en Cuba}

La inclusión de la cooperativa en Cuba, con posterioridad al triunfo de la Revolución, es un resultado del carácter socialista adoptado por el Estado cubano y cuyo fin va dirigido a superar «...la división de los hombres en poseedores de los medios de producción y desposeídos de

28 Cfr. Artículo 19 del Decreto Ley n. ${ }^{\circ} 234$ de 2003, De la maternidad de las trabajadoras, publicado en http://www.sld.cu/galerias/pdf/sitios/insat/dl-234-2003.pdf y consultado en fecha 30 de mayo de 2012. 
ellos» ${ }^{29}$. A tal propósito debe contribuir esta forma de propiedad a la par que fomenta «las relaciones personales [que] se basen en la colaboración y ayuda mutua» 30 .

La cooperativa en Cuba es reconocida por el artículo $20^{31}$ del magno texto cubano como un tipo de propiedad que "...constituye una forma avanzada y eficiente de producción socialista», a pesar de lo cual se ha limitado en su implementación solo al especio rural ${ }^{32}$. Es por ello que para comprender la relación particular cooperativa-género en este terreno, especialmente delimitado, se hace necesario examinar la situación de las féminas en el campo, sector que dentro de la sociedad, en su conjunto, presenta características y rasgos propios especialmente en cuanto a roles asignados.

La vida en las zonas rurales de la Isla ha experimentado grandes mejorías, muchas de las cuales tienen una incidencia directa en las labores tradicionalmente femeninas: "Se han creado servicios básicos de apoyo al hogar, así como se ha continuado la distribución de efectos

29 Álvarez Tabío, F. Comentarios a la Constitución socialista cubana, Ed. Pueblo y Educación, La Habana, 1989, p. 84.

30 Ibídem.

31 «Los agricultores pequeños tienen derecho a asociarse entre sí, en la forma y con los requisitos que establece la ley, tanto a los fines de la producción agropecuaria como a los de obtención de créditos y servicios estatales.

Se autoriza la organización de cooperativas de producción agropecuaria en los casos y en la forma que la ley establece. Esta propiedad cooperativa es reconocida por el Estado y constituye una forma avanzada y eficiente de producción socialista.

Las cooperativas de producción agropecuaria administran, poseen usan y disponen de los bienes de su propiedad, de acuerdo con lo establecido en la ley y en sus reglamentos.

Las tierras de las cooperativas no pueden ser embargadas ni gravadas y su propiedad puede ser transferida a otras cooperativas o al Estado, por las causas y según el procedimiento establecido en la ley.

El Estado brinda todo el apoyo posible a esta forma de producción agropecuaria.»

Constitución de la República de Cuba, consultada en http://www.parlamentocubano. cu/index.php?option=com_content\&view=article\&id=1418\&ltemid=83 en fecha 25 de mayo de 2012.

32 Sobre el debate al respecto al carácter agrario exclusivo de la cooperativo en Cuba «...las interpretaciones doctrinales al texto constitucional cubano de 1976 habían estado divididas (...) Para algunos «la Constitución reconoce a la cooperativa como una propiedad agraria, sin hacerla extensiva a ningún otro tipo de explotación económica», viéndose así —en la definición constitucional de la cooperativa - un límite para la expansión legal de la figura a otros sectores de la economía; para otros, en cambio, «la enumeración constitucional de las formas de propiedad no es taxativa, por lo cual es factible que la ley establezca la autorización para otras modalidades o posibilidades de la propiedad cooperativa.»

RodríGuez MusA, O., ob. cit., p. 66. 
electrodomésticos, que facilitan las labores hogareñas y con ello también incentivan compartir las tareas del hogar en mejores condiciones. Se han concluido alrededor de 300 obras sociales, 45 policlínicos reparados y ampliados, amplio presupuesto se ha derivado para obras de alto impacto social. Más de 3.000 acueductos que garantizan el agua potable clorada han sido». ${ }^{33}$

Las mujeres eran el $47 \%$ de la población rural en $2010^{34}$. En cifras su presencia en el sector cooperativo campesino puede resumirse al porcentaje que representan del total de los socios de las diversas formas cooperativas existentes, siendo así que «en las CPA era el 17,4\% en 1999; en las CCS el 8,2\% en igual año; el 18,5\% en las UBPC agropecuarias y el $16,5 \%$ en las cañeras» ${ }^{35}$ de forma que "actualmente son socias 39.623 mujeres, con iguales oportunidades, derechos y posibilidades que los socios hombres» ${ }^{36}$. Estas cifras no son desdeñables, pero si se comparan con los porcentajes de féminas insertadas en otros sectores de la vida del país contrastan inmediatamente.

En pos de coadyuvar a la incorporación de la mujer a las labores del sector agropecuario la Asociación Nacional de Agricultores Pequeños (ANAP) «creó la Cátedra de Género en la Escuela Nacional de Capacitación, a través de la que se transversaliza la enseñanza de dicho enfoque para todos los planes y programas, en los diferentes cursos que allí se imparten para los cuadros y dirigentes de base de esa Asociación. ${ }^{37} 38$

En el plano legal ordinario las normas ordenadoras de las cooperativas cubanas - Ley n. ${ }^{\circ} 36$ Cooperativas Agropecuarias de 22 de julio de 1982 que fuera derogada por la Ley n. ${ }^{\circ} 95$ Cooperativas de Producción Agropecuaria y de Créditos y Servicios de 2 de noviembre de 2002 y el Decreto Ley 142, sobre las Unidades Básicas de Producción Coo-

33 Informe de Cuba a la Mesa Directiva sobre la mujer de América Latina y el Caribe de la CEPAL. Informe de Cuba, Santiago, Chile, 2010, publicado en www.eclac.cl/ mujer/noticias/noticias/1/41081/Cuba.pdf y consultado en fecha 20 de mayo de 2012.

34 Anuario Estadístico de Cuba 2010, publicado en http://www.one.cu/aec2010/ esp/03_tabla_cuadro.htm y consultado el 30 de mayo de 2012.

35 Pérez Rolo, Marta y Díaz, Elena, ob. cit., p. 67

36 Informe de Cuba..., ob. cit.

37 Ibidem.

38 Otras organizaciones cuya labor se materializa en el sector agrario también han instrumentado estrategias de género. V. gr.: «La Asociación Cubana de Producción Animal (ACPA), presidida por una mujer, cuenta asimismo con una Estrategia de Género, la cual se aplica en todas las estructuras. Tiene instituido el Premio de la Mujer Rural, el que significa un estímulo para destacar a aquellas que se desempeñan en el campo científico, técnico y práctico de producción agroalimentaria. La ACTAF, Asociación Cubana de Técnicos Agrícolas Forestales tiene también su Estrategia de Género, privilegiando el acceso de las mujeres a dicha actividad.» Informe de Cuba., ob. cit. 
perativa, de 20 de septiembre de 1993 - no han ofrecido una regulación única de los principios cooperativos, aunque han articulado una lógica de funcionamiento en torno a principios como el de democracia cooperativista, solidaridad humana y unión de los intereses personales con los colectivos en la cooperativa ${ }^{39}$ que ciertamente podría perfeccionarse tomando como referencia aspecto tratados en la Declaración sobre la Identidad Cooperativa de 1995.

En las citadas legislaciones se ha reconocido que pueden formar parte de ellas, sin distinción de sexo, «el cónyuge, hijos y demás familiares del cooperativista» ${ }^{40}$ de los afiliados y que estas se proyectaran en su trabajo hacia el «mejoramiento de las condiciones de vida de los cooperativistas y sus familiares... [promoviendo] la participación consciente de sus miembros en las tareas económicas y sociales de la nación, la localidad y la comunidad.» ${ }^{41}$ A la par que «...trabajan en la educación de sus miembros para el cumplimiento de los principios que las rigen, así como en su capacitación técnica y la formación de sus cuadros. $)^{42}$

Aun cuando toda la labor antes señalada y los resultados alcanzados son significativos, una investigación desarrollada en el este del país sobre la incorporación femenina al trabajo en áreas agrícolas, señaló como causas desestimulantes «la sobrecarga doméstica, la persistencia de conductas y actitudes discriminatorias hacia la mujer en el empleo, la poca capacitación para el empleo y la existencia de inadecuadas condiciones para el trabajo» ${ }^{43}$.

En el Estudio sobre los valores de género en dos cooperativas cubanas cuyos resultados publicaran Marta Pérez Rolo y Elena Díaz ${ }^{44}$ se hace evidente un contraste entre los logros alcanzados por las mujeres y la permanencia de concepciones cultural e históricamente construidas, que limitan su plena realización.

39 Cfr. ROJAs JIMÉNEZ, A. «La cooperativa como institución agraria en Cuba: principios normativos que la sostienen», Boletín de la Asociación Internacional de Derecho Cooperativo, n. ${ }^{\circ} 44 / 2010$, Bilbao, pp. 67-82.

40 Artículo 15. Ley n. ${ }^{\circ} 36$ Cooperativas Agropecuarias, publicada en http://www. parlamentocubano.cu/index. php?option=com_content\&view=article\&id=252:ley-no-36cooperativas-agropecuarias\&catid=46:leyes\&ltemid=79 en fecha 28 de mayo de 2012.

41 Artículo 6. Ley n. 95 Cooperativas de Producción Agropecuaria y de Créditos y Servicios, publicada en http://www.parlamentocubano.cu/index.php?option= com_content\&view=article\&id=307:ley-no95-cooperativas-de-producion-agropecuariay-de-creditos-y-servicios\&catid=46:leyes\&ltemid=79, y consultada en 29 de mayo de 2012.

42 Artículo 7, ibídem.

43 Pérez Rolo, Marta y Díaz, Elena, ob. cit., pp. 67-68

44 Cfr. Pérez Rolo, Marta y Díaz, Elena, ob. cit., pp. 80-90. 
Pues si de un lado se observan logros en cuanto a que:

— «Se aprecia que hay una satisfacción creciente entre las mujeres por su participación social. $\rangle^{45}$

— «Se muestra un sentimiento de independencia» ${ }^{46} \mathrm{y}$

— «Se observa una tendencia, más acentuada en las trabajadoras de la UBPC, a que las mujeres se autovaloren como capaces de desempeñar labores de dirección y técnicas. ${ }^{47}$

De otro se mantienen concepciones que hacen que:

— «En tiempos de zafra, ambos miembros de la pareja aumentan sus jornadas laborales, aunque permanece la sobrecarga femenina doméstica y familiar. ${ }^{48}$

— «La mayoría de las aspiraciones de las mujeres se dirigen a la esfera familiar y doméstica.» 49

— «Se mantiene la imagen del hombre proveedor.» 50

- «Se mantiene, incluso, en ellas, la ubicación de los hombres fuera de tareas típicamente femeninas de acuerdo a la división tradicional, incluyendo la atención a niños. ${ }^{51}$

En palabras de las propias autoras del Estudio «a pesar de las dificultades que aún persisten en la incorporación femenina al empleo socialmente retribuido en el área rural, los obstáculos son más fuertes en la persistencia de tradiciones que en las posibilidades de participación a partir de la existencia real de una plataforma estructural que ofrece condiciones y oportunidades de transformación de roles. ${ }^{52}$

Esto está dado fundamentalmente porque "Sin desconocer la realidad de esos progresos concientes o impuestos por la sociedad, todavía una mayoría significativa de hombres del campo se comportan con una masculinidad hegemónica bien acentuada y asentada en los viejos patrones familiares aprendidos desde la infancia, en tanto las mujeres, también en una sorprendente mayoría, aún las que han superado esquemas tradicionales de vida, siguen someti-

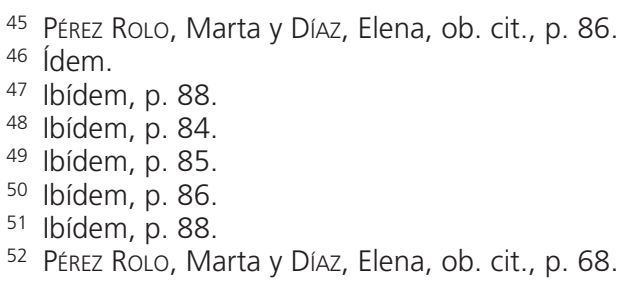


das al poder masculino, quizás no en igual grado y condición que sus antecesoras». ${ }^{53}$

Lo antes expuesto demuestra que las políticas para enfrentar las concepciones de género, y las consecuencias derivadas de ellas, en el campo cubano tienen un impacto más demorado que en otros sectores de la vida del país donde el camino andado permitiría un avance más acelerado del desarrollo de las potencialidades de género presentes en las cooperativas, tomando en cuenta los niveles de inserción, preparación y los cambios en cuanto a percepciones culturales sobre roles ya operados en ellos.

De forma que en cuanto a la relación género-cooperativa en Cuba puede afirmarse que:

- La cooperativa ha demostrado en el marco legal, cultural, social y político cubano que es posible experimentar un sensible cambio en determinados enfoques de género, no obstante el hecho de que esta se haya desarrollado exclusivamente en el sector rural no ha permitido que esta despliegue con mayor amplitud sus posibilidades.

Razón por la que conviene examinar las posibilidades que tendría la relación género-cooperativa ante una normativa que permitiera la extensión de esta figura a otros sectores de la economía como lo disponen los Lineamientos de la Política Económica y Social del Partido y la Revolución aprobados en el VI Congreso del Partido Comunista de Cuba .

\section{Género y cooperativa: potencialidades ante la regulación de nuevas formas de cooperativas en Cuba}

En los Lineamientos de la Política Económica y Social del Partido y la Revolución, aprobados el 18 de abril de 2012 por el VI Congreso

53 Álvarez, M. Masculinidades cubanas: El machismo guajiro. Ponencia en la Primera Jornada Cubana de Estudio sobre Masculinidades (versión digital CD) CENESEX, Ciudad de la Habana, 2006. Citado por CASTAÑedA Pérez, I. Aproximación al estudio de la equidad de género en la ANAP: premisas para un diagnóstico. Tesis en opción al Título de Máster en Gestión y Desarrollo de Organizaciones Cooperativas, 2007, publicada en http://www.flacsoandes.org/dspace/bitstream/10469/1169/1/ Aproximaci\%C3\%B3n\%20al\%20estudio \%20de \% 20la \% 20 equidad $\% 20$ de $\% 20$ g\%C3\%A9nero...\%20lsabel\%20Casta\%C3\%B1eda.pdf y consultada en fecha 25 de mayo de 2012. 
del Partido Comunista de Cuba ${ }^{54}$ como directrices para el perfeccionamiento del modelo socioeconómico cubano para los próximos años figuran bajo el título de "LAS COOPERATIVAS» cinco puntos, del 25 al 29, que incluyen a estas entidades como parte de un nuevo «MODELO DE GESTIÓN ECONÓMICA» con el que el país se propone elevar la productividad del trabajo.

Sobre estas bases se ha venido trabajado por parte de la Comisión Permanente de Implementación y Desarrollo de los Lineamientos cuyo Presidente, Marino MuriLto, anunció el 31 de marzo de 2012 en reunión ampliada del Consejo de Ministros la creación experimental de cooperativas fuera del sector agropecuario, sosteniendo que para cada experimento se han diseñado los principios fundamentales, reservando el papel regulador del Estado y el gobierno según corresponde ${ }^{55}$. Lo cual está en consonancia con 36 de los 313 Lineamientos aprobados, poniendo de relieve la importancia general que se le atribuye a la figura cooperativa.

Según los Lineamientos las cooperativas de primer grado se desarrollarían "en diferentes sectores» ${ }^{56}$ y las de segundo grado en "actividades complementarias afines o que agreguen valor a los productos y servicios de sus socios (de producción, servicios y comercialización), o realizar compras y ventas conjuntas con vistas a lograr mayor eficiencia» 57

Estas cooperativas se desarrollarían fundamentalmente en sectores que hoy ocupaban los trabajadores por cuenta propia $^{58}$ y otros que

54 Vid. Lineamientos de la Política Económica y Social del Partido y la Revolución, aprobados el 18 de abril de 2012 en http://www.prensa-latina.cu/Dossiers/Lineamientos VICongresoPCC.pdf

${ }_{55}$ Cfr. «Cuba: Aprueba consejo de Ministros creación experimental de cooperativas no agropecuarias». Tomado del Noticiero del Mediodía de la Televisión Cubana, publicado en http://www.youtube.com/watch?v=7FVzkQhfkTQ y consultado en fecha 20 de junio de 2012.

56 «Lineamiento 25», Lineamientos..., ob. cit.

57 «Lineamiento 29», Lineamientos..., ob. cit.

58 «Al analizar el nuevo contexto, debemos entender el importante potencial que significan estos trabajadores individuales, pequeños y dispersos, para la configuración de las emergentes cooperativas cubanas. Ellos pudieran constituir en la ciudad, el sujeto homólogo del pequeño agricultor en el campo, salvando las diferencias relativas a la propiedad de los bienes que decidan aportarse a la actividad cooperada. Las razones económicas, políticas y sociales que aconsejan y justifican la instrumentación legal del derecho de asociarse en cooperativa a los segundos, debe valer — con igual fuerzapara los primeros, ya que — en última instancia — se trata de asegurar la eficacia del carácter socialista del texto constitucional cubano, ponderando la realización colectiva del derecho al trabajo...» Rodríguez Musa, O. ob. cit., pp. 77-78. 
hasta "ahora tutela el estado». ${ }^{59} \mathrm{Al}$ examinar sus perspectivas, ya sean de producción o servicios, debe partirse de que el sector del cuentapropismo cuentan que en la actualidad son más de un centenar de actividades y aunque no todas presentan posibilidades de establecer cooperativas buena parte de ellas podrían servir para emprendimientos económicos colectivos, lo que hace pensar que el número potencial de implicados en las futuras cooperativas sería cuando menos relevante60.

Actualmente el gobierno trabaja en una ley de cooperativas ${ }^{61}$ para la cual los resultados de los actuales experimentos cooperativos deben ser fuente de referencias. En cualquier caso es importante que esta futura norma tome en consideración varios contenidos constitucionales ${ }^{62}$ a fin de que estas nuevas cooperativas se inserten, completa y favorablemente, en el sistema socialista cubano. Entre las cuestiones que no deben ser pasadas por alto está el trato no discriminatorio de la mujer, que figuraría en su doble concepto de derivación del principio de igualdad $^{63}$ y del derecho al trabajo. ${ }^{64}$

La misma situación descrita supra ${ }^{65}$ sobre los niveles de calificación alcanzados por las mujeres en Cuba, unido a su nivel de presencia en el sector del cuentapropismo, permiten comprender el alto nivel de participación que estas podrían alcanzar en las cooperativas que se conformen a partir de dichos sectores, lo que sería el punto de partida para que todas las potencialidades descritas de flexibilidad, inclusión, empo-

59 El presidente de la Comisión Constitucional de la Asamblea Nacional, José Luis Toledo, explica los Lineamientos, publicado en http://www.parlamentocubano.cu/ index.php?option=com_content\&view=article\&id=3336:el-presidente-de-la-comisionconstitucional-de-la-asamblea-nacional-jose-luis-toledo-explica-los-lineamientos y consultado en fecha 20 de junio de 2012.

60 "Al cierre de febrero en la isla hay 371.200 trabajadores "por cuenta propia", como se denomina aquí a los empleados fuera del sector estatal, informó esta semana el viceministro del MTSS, José Barreiro». Número de cuentapropistas sigue creciendo en Cuba, publicado en http://www.cubadebate.cu/noticias/2012/04/01/numero-decuentapropistas-sigue-creciendo-en-cuba/ y consultado en fecha 20 de junio de 2012.

61 Cfr. El presidente de la Comisión..., ob. cit.

62 Vid. Rodríguez Musa, O. ob. cit., pp. 71-72.

63 Cfr. CAPÍTULO VI, Constitución de la República de Cuba.

64 Artículo 45. El trabajo en la sociedad socialista es un derecho, un deber y un motivo de honor para cada ciudadano. El trabajo es remunerado conforme a su calidad y cantidad; al proporcionarlo se atienden las exigencias de la economía y la sociedad, la elección del trabajador y su aptitud y calificación...

Ibídem.

65 IV. La perspectiva de género en Cuba. Condiciones materiales y tratamiento legal. 
deramiento y valorización presentes en las cooperativas ${ }^{66}$ se llevaran a un nivel superior dentro de la realidad cubana.

Si partimos de que una de las fuentes de las futuras cooperativas serían el empleo por cuenta propia tendríamos una fuerza femenina en activo que era del $20 \%$ total de trabajadores en $2010^{67}$, cifra que habrá variado sustancialmente con la ampliación de actividades experimentado por este sector de la economía tomando en consideración V. gr. que entre los empleos más solicitados por los cuentapropistas «está la elaboración y venta de alimentos y la contratación de la fuerza de trabajo que le sirve de apoyo... ${ }^{68}$ o sea la esfera de los servicios donde en 2010 las mujeres eran el 40,20\% de la fuerza de trabajo. ${ }^{69}$

Si a ellos sumamos que «El gobierno cubano prevé este año un incremento de 240.000 trabajadores no estatales, los que sumados a los actuales superarán el medio millón..... ${ }^{70}$ y aplicamos un cálculo proporcional en base a cifras similares a las antes mencionadas podemos entender que la cantidad de féminas incorporadas sería, desde el inicio, superior al que actualmente se vinculan a las formas cooperativas tradicionales.

A lo anterior habría que añadir que la situación de roles en este sector del trabajo por cuenta propia es diferente al que se da en el campo, toda vez que «....muchas de ellas, [actúan como] las verdaderas dueñas y gerentes de sus establecimientos, aunque sus esposos aparecían formalmente como tales..$^{71}$ De hecho "... hay una gran diferencia entre el sector informal cubano y sus rasgos en otros países; por la calificación de estas mujeres, el papel protagónico que desarrollan y porque el trabajo informal no se ejerce para lograr un nivel de supervivencia.... $\rangle^{72}$

Las particularidades de los sectores y fuentes de que han de nutrirse las nuevas cooperativas a desarrollarse en Cuba permiten esperar que:

- Los resultados de estas en materia de género sean cualitativamente superiores toda vez que en los sectores en que desarro-

66 Vid. supra III.2 Cooperativa y género. Principios cooperativos y posibilidades para desarrollar un enfoque de género.

67 Anuario Estadístico de Cuba 2010, publicado en http://www.one.cu/aec2010/ esp/07_tabla_cuadro.htm y consultado en fecha 20 de junio de 2012.

68 Número de cuentapropistas sigue creciendo en Cuba, publicado en http://www. cubadebate.cu/noticias/2012/04/01/numero-de-cuentapropistas-sigue-creciendo-encuba/ y consultado en fecha 20 de junio de 2012.

69 Anuario Estadistico..., ob. cit.

70 Número de cuentapropistas..., ob. cit.

71 Pérez Rolo, Marta y Díaz, Elena. ob. cit., p. 66.

72 Ibídem, p. 67-68. 
Ilarían el nivel de formación y de capacidad demostrada de la féminas garantizaría un nivel superior de partida, y la preparación y actitud de estas es ideal para hacer un uso más acabado de las posibilidades de desarrollo personal-profesional que las cooperativas les ofrecen, frente a lo cual el Derecho puede y debe ser un factor de estimulación partiendo de una coherente regulación de esta institución jurídica conforme a los marcos legales existentes y los principios cooperativos que encierran esas potencialidades.

\section{A modo de conclusiones}

Dentro del mundo laboral se hace necesario que las formas de organización y planificación del mismo, partiendo de la legislación particular de la actividad que se trate, se adapten aún más a las necesidades de pleno desarrollo de las mujeres, de forma que la realización personal y profesional de ellas no supongan una disyuntiva excluyente.

Las cooperativas suponen un importante espacio de desarrollo de potencialidades en cuanto al enfoque de género toda vez que están pensadas, desde su esencia, para el mejor desarrollo de sus miembros y de la sociedad en general, sin que la parte económico-productiva de las mismas pueda desnaturalizar su esencia humanista y socialista.

En la actualidad Cuba presenta una importante labor en materia de género, incluido el sector cooperativo, pero la limitación de esta solo a las labores agropecuarias, donde las concepciones tradicionales de los roles se muestran más resistentes, no ha permitido que se exploten al máximo sus potencialidades a pesar de las políticas llevadas a cabo con este fin.

Las perspectivas de una ampliación legal de las posibilidades de desarrollo cooperativo contempladas en los Lineamientos de la Política Económica y Social del Partido y la Revolución permitirían operar al Derecho, como elemento autorizante, ordenador y estimulante, jugar un papel relevante en que esto vaya aparejado de una mayor inclusión y empoderamiento de las mujeres dentro del sector cooperativo, a partir de una regulación que garantice los marcos adecuados para el desarrollo de todas las potencialidades sociales y culturales, más allá de las económicas, presentes en esta forma de emprendimientos económicos colectivos. 


\section{Bibliografía}

\section{Textos}

$\mathrm{ACl}$. «Declaración sobre la identidad cooperativa», Manchester, septiembre de 1995, reproducida y comentada por El Hogar Obrero: Cooperativa de Consumo, Edificación y Crédito, Ltda., en http://www.elhogarobrero1905.org. ar, consultada en diciembre de 2009.

AstelarRa, J. "Estado y políticas de género», publicado en Temas n.os 37-38/ abril-septiembre de 2004.

Álvarez Tabío, F. Comentarios a la Constitución socialista cubana, Ed. Pueblo y Educación, La Habana, 1989.

CABEZAS CRUZ, Evelio. "Evolución de la mortalidad materna en Cuba». Revista Cubana Salud Pública, Ciudad de La Habana, v. 32, n. 1, marzo de 2006. Disponible en <http://scielo.sld.cu/scielo.php?script=sci_ arttext\&pid=S0864-34662006000100005\&lng=es\&nrm=iso $>$. Consultada el 19 de mayo de 2012.

Caram León, T. Empoderamiento femenino en Cuba. Criterios para su análisis en las Cooperativas. FLACSO-Cuba, p. 1, publicado en http://www.flacso. uh.cu/sitio_revista/num2/articulos/art_TCaram.pdf, consultado en fecha 25 de mayo de 2012.

Castañeda Pérez, I. Aproximación al estudio de la equidad de género en la ANAP: premisas para un diagnóstico, Tesis en opción al Título de Máster en Gestión y Desarrollo de Organizaciones Cooperativas, 2007, publicada en http://www.flacsoandes.org/dspace/bitstream/10469/1169/1/ Aproximaci\%C3\%B3n\%20al\%20estudio\%20de\%20la\%20equidad\%20 de\%20g\%C3\%A9nero...\%20lsabel\%20Casta\%C3\%B1eda.pdf y consultada en fecha 25 de mayo de 2012.

Fernández Bulté, J. Teoría del Estado y el Derecho. Segunda Parte Teoría del Derecho, Editorial Félix Varela, La Habana, 2004.

MAsino, M.A. «Los aportes de Antonio Gramsci para una epistemología materialista del Derecho», publicado en Introducción a la epistemología del Derecho. Dirección de Publicaciones, Universidad Nacional del Rosario, 1988.

MINSAP. Anuario Estadístico de Salud 2010. Consultado en http://files.sld.cu/ dne/files/2011/04/anuario-2010-e-sin-graficos1.pdf, en fecha 26 de mayo de 2012.

TshibILONDI NGoYI, A. "La filosofía y los problemas de género en África». Temas n. ${ }^{\text {os }}$ 37-38/abril-septiembre de 2004.

Pérez Rolo, Marta y Díaz, Elena. "Estudio sobre los valores de dirección y de género en las cooperativas cubanas», Cuaderno pedagógico, volumen 2IRECUS FLACSO/CUBA, Université de Sherbrooke Universidad de La Habana, uniRcoop, 2006.

Rodríguez Musa, O. La cooperativa como figura jurídica. Perspectivas constitucionales en Cuba para su aprovechamiento en otros sectores de la economía nacional diferentes al agropecuario. Dikinson S.L., Madrid, 2011. 
Rodríguez Reyes, I. «Relaciones de género en la familia cubana: ¿espacio de igualdad o desigualdades?», Temas n. ${ }^{\circ}$ 48, octubre-diciembre de 2006.

SÁNCHEZ VÁZQUEZ, A. "Reflexiones- ¿intempestivas?: sobre la igualdad y la desigualdad». En Entre la realidad y la utopía, Editorial de Ciencias Sociales, La Habana.

VILNITZKY, M. et al. Mujer y cooperativismo, consultado en http://www.empresa ytrabajo.coop/024/dos02401.asp en fecha 27 de abril de 2012.

\section{Otros documentos}

Anuario Estadístico de Cuba 2010, publicado en http://www.one.cu/aec2010/ esp/03_tabla_cuadro.htm y consultado el 30 de mayo de 2012.

Cuba: Aprueba consejo de Ministros creación experimental de cooperativas no agropecuarias. Tomado del Noticiero del Mediodía de la Televisión Cubana, publicado en http://www.youtube.com/watch?v=7FVzkQhfkTQ y consultado en fecha 20 de junio de 2012.

El presidente de la Comisión Constitucional de la Asamblea Nacional, José Luis Toledo, explica los Lineamientos, publicado en http://www.parlamento cubano.cu/index.php?option=com_content\&view=article\&id=3336:elpresidente-de-la-comision-constitucional-de-la-asamblea-nacional-joseluis-toledo-explica-los-lineamientos y consultado en fecha 20 de junio de 2012.

Glosario de términos relacionados con la transversalidad de género. Proyecto Equal «En clave de culturas», Secretaría Técnica del Proyecto Equal «En Clave de Culturas», 2007.

Informe de Cuba a la Mesa Directiva sobre la mujer de América Latina y el Caribe de la CEPAL. Informe de Cuba, Santiago, Chile, 2010, publicado en www.eclac.cl/mujer/noticias/noticias/1/41081/Cuba.pdf y consultado en fecha 20 de mayo de 2012.

Lineamientos de la Política Económica y Social del Partido y la Revolución, aprobados el 18 de abril de 2012 en http://www.prensa-latina.cu/Dossiers/ LineamientosVICongresoPCC.pdf

Número de cuentapropistas sigue creciendo en Cuba, publicado en http:// www.cubadebate.cu/noticias/2012/04/01/numero-de-cuentapropistas-sigue-creciendo-en-cuba/ y consultado en fecha 20 de junio de 2012.

\section{Legislación}

Constitución de la República de Cuba, consultada en http://www.parlamentocubano.cu/index.php?option=com_content \&view=article\&id=1418\&/temi $\mathrm{d}=83$ en fecha 25 de mayo de 2012.

Ley n. ${ }^{\circ} 36$ Cooperativas Agropecuarias, publicada en http://www.parlamento cubano.cu/index.php?option=com_content\&view=article\&id=252:ley- 
no-36-cooperativas-agropecuarias\&catid=46:leyes\&ltemid=79 en fecha 28 de mayo de 2012.

Ley n. ${ }^{\circ} 49$ Código de Trabajo, publicada en http://www.parlamentocubano.cu/ index. php?option=com_content\&view=article\&id=264:ley-no-49-codigode-trabajo\&catid=46:leyes\&ltemid=79 y consultada en fecha 30 de mayo de 2012.

Ley n. 95 Cooperativas de Producción Agropecuaria y de Créditos y Servicios, publicada en http://www.parlamentocubano.cu/index.php?option=com_ content\&view=article\&id=307:ley-no95-cooperativas-de-producionagropecuaria-y-de-creditos-y-servicios\&catid=46:leyes\&ltemid=79, y consultada en fecha 29 de mayo de 2012.

Decreto Ley $n{ }^{\circ} 234$ de 2003 De la maternidad de las trabajadoras, publicado en http://www.sld.cu/galerias/pdf/sitios/insat/dl-234-2003.pdf y consultada en fecha 30 de mayo de 2012. 